\title{
EDITORIAL
}

\section{Alpha-1-antitrypsin replacement therapy: will its efficacy ever be proved?}

\author{
D.C.S. Hutchison*, M.D. Hughes**
}

The study concerned with the treatment of alpha-1antitrypsin (AT) deficiency, which appears in this issue of the Journal [1], requires that we all give serious thought to this controversial and difficult topic. Before dealing directly with the issues raised by the design of this study, however, it is necessary to give some account of the events that led up to it.

AT deficiency is a hereditary disorder that can lead to the development of disabling pulmonary emphysema at a relatively early age. AT is the main serum inhibitor of proteolytic enzymes and one of its most important functions is thought to be the inactivation of the potent elastase produced by polymorphonuclear leucocytes. In the severe form of the deficiency (subjects homozygous for Pi type $\mathrm{Z}$ ) the serum AT concentration may be no more than 10-20\% of normal and in these circumstances the pulmonary elastic tissue may be degraded by the unopposed action of the leucocyte elastase. Cigarette smoking can seriously exacerbate this effect.

The disability and early mortality that can result from this disorder make it entirely logical to attempt replacement of the missing serum protein fraction and potentially suitable therapy has been available for some years [2]. The current commercial products require intravenous administration and have a half-life of no more than 5 days. In addition, such treatment might have to be administered for many years and perhaps for the lifetime of the patient. There has been extensive debate on how this therapy should be evaluated and in particular whether a randomized controlled trial should be performed. The problems of such a trial were recognized to be substantial; emphysema usually evolves slowly over a period of many years and any trial requiring serial evaluation of lung function would need to continue for a corresponding period of time.

The possibility of conducting a randomized controlled trial was discussed by a workshop supported by the USA National Heart, Lung and Blood Institute (NHLBI) [3]. Pilot studies had already shown that, in patients with severe deficiency, the serum AT concentration could be raised from a mean of $37 \mathrm{mg} \cdot \mathrm{dL}^{-1}$ to $108 \mathrm{mg} \cdot \mathrm{dL}^{-1}$ by intravenous infusion of $4 \mathrm{~g}$ of AT replacement [2, 4]. The members of the Workshop considered that the optimal form of trial would be one carried out in patients

Correspondence: D.C.S. Hutchison, Dept of Respiratory Medicine, King's College School of Medicine, London SE5 9PJ, UK.

*Dept of Respiratory Medicine, King's College School of Medicine, London SE5 9PJ, UK. **Medical Statistics Unit, Dept of Epidemiology and Population Health, London School of Hygiene and Tropical Medicine, Keppel Street, London WC1E 7HT. with relatively mild disease and that this would require measurement of the decline in forced expiratory volume in one second (FEV1) in treated and untreated groups over a period of some years. At that time, there was no data on the natural rate of decline in lung function in AT deficient patients and the authors, while recognizing the possible errors of this approach, were obliged to base their estimates of sample size on values obtained in cases of non-AT deficient chronic obstructive pulmonary disease (COPD) from previous studies. They came to the conclusion that a total of over 300 patients would be needed to show a $50 \%$ reduction in the rate of decline in FEV1, in a study lasting for 5 yrs.

In a series of AT deficient cases published a few years later [5], 60 cases homozygous for Pi type Z, who had been followed up for some years, were identified; their mean rate of decline in FEV1 was $93 \mathrm{~mL} \cdot \mathrm{yr}^{-1}$ with a large standard deviation $\left(143 \mathrm{~mL} \cdot \mathrm{yr}^{-1}\right)$, as is often found in this type of survey. The authors concluded again that large numbers would be required, 253 in both treated and untreated groups in order to detect a $40 \%$ reduction in the rate of decline in FEV 1 in a study lasting 3 yrs. It was pointed out that, nevertheless, this would be far preferable to a mortality study where much more severely affected patients would be involved and the numbers required would be even greater.

The production of AT replacement therapy on a commercial scale was developed by Cutter Biological, Miles Inc. (subsequently Bayer AG, Leverkusen, Germany) [6] and by the Centre Régional de Transfusion Sanguine (Lille, France) [7]; the commercial forms of AT have similar activity to the native protein. Pasteurization was shown to bring about rapid inactivation of retroviruses including human immunodeficiency virus (HIV) [8] and the serum AT levels in deficient subjects could be raised to normal without serious adverse reactions $[9,10]$.

Alongside the development of commercial AT replacement therapy, a number of studies of the natural history of the disease in several countries appeared in the literature [5, 11-13]. The average rates of decline in FEV1 were of the same order in the majority of studies but there were wide variations among patients, as demonstrated by the large standard deviations. Further calculations suggested that the required number of patients was perhaps not so great as previously envisaged and could be achieved by a multinational European study [14]; a parallel group study was recommended with patients randomized to treatment and nontreatment groups, ideally on a double-blind basis, the patients having FEV1 ranging $35-75 \%$ of the reference value, with 
spirometry performed at monthly intervals. A study on these lines involving patients in the Netherlands and Denmark is in progress.

Commercial AT replacement therapy has, for some years, been licensed for general use in AT deficient subjects both in the USA and in Germany. The product has, therefore, been administered to a large number of patients in both countries even though there has been no formal study of its efficacy. An attempt to remedy this situation has led to the combined German-Danish study reported in this issue [1]. The aim of the study was to compare two cohorts of AT deficient subjects, the German cohort consisting of $198 \mathrm{PiZ}$ homozygotes treated with AT replacement therapy, while the 97 untreated subjects in the Danish cohort were drawn from their long established national registry of AT deficient patients. The rate of decline in FEV 1 was $53.0 \mathrm{~mL} \cdot \mathrm{yr}^{-1}$ in the treated group and $74.5 \mathrm{~mL} \cdot \mathrm{yr}^{-1}$ in the untreated, a difference that is statistically significant. The authors have pointed out that this was not a randomized study and they have, indeed, recognized the limitations of their approach. They took a number of steps to try to ensure that the two groups were comparable, important points being their selection of index cases and of exsmokers, thus ruling out the unpredictable effects of smoking on the change in FEV1. They also drew attention to differences between the two groups in terms of gender, follow-up time and initial FEV1 but concluded that these factors did not influence the results. Other factors that might have been considered include the timing of the spirometry measurements; the Danish group were required to have "at least two spirometries at least 1 yr apart", whereas in the German group measurements were made every 6 months. In the German group the measurements were made after bronchodilator administration, but this aspect is not mentioned in relation to the Danish group; nor do asthmatic symptoms appear to have been considered. It is particularly difficult, under the conditions of this trial, to allow for the possibility of differences in ancillary care both between countries and between the individual centres. All these sources of imbalance would have been eliminated in a properly designed randomized controlled trial.

One of the pitfalls of retrospective selection of patients is well illustrated by examination of the data reported by the same group of Danish workers 2 yrs previously [15]. The patients described there are of similar origin to those in the current German-Danish study; they were drawn from the same national registry with the same criteria for Pi type, age and spirometry. In the 74 index cases who were exsmokers the rate of decline in FEV1 was reported as $59.1 \mathrm{~mL} \cdot \mathrm{yr}^{-1}$, as opposed to $74.5 \mathrm{~mL} \cdot \mathrm{yr}^{-1}$ in the current paper. No difference between treatment and control groups would have been demonstrated if the 1995 Danish patients had been used for the comparison.

In 1988, the National Heart Lung and Blood Institute (NHLBI) began the sponsorship of a 37 centre National Registry of AT deficient patients [16]. It had been decided that a randomized controlled trial of replacement therapy would not be possible in the USA on the grounds that the calculated number (300-500) of patients required for a trial $[3,5]$ could not have been obtained. Such a trial would in any case have been very difficult to con- duct in the face of the decision by the Food and Drug Administration of the USA to allow the product to be used in the treatment of these patients; indeed more than $20 \%$ of the patients were already receiving AT replacement therapy at the time of enrolment into the Registry. The investigators were nevertheless able to enrol over 1,000 AT deficient subjects in the space of 44 months, about $40 \%$ of whom had an FEV1 of $30-70 \%$ of the predicted value [17], and would thus have been considered suitable for recruitment into a randomized controlled trial.

"Uncontrolled trials are usually over-optimistic" [18] and this author quotes several examples of nonrandomized trials in which a particular treatment was reported favourably but where subsequent randomized trials showed little or no advantage. The arguments against conducting a controlled trial of this therapy are now familiar. The recruitment of sufficient subjects is essential for any clinical trial and this could certainly have been achieved by wider European (or even trans-Atlantic) cooperation. The cost and duration of such trials are also important constraints, though these apply to uncontrolled trials in equal measure. The fact that the therapeutic agent may have been in short supply only appears to strengthen the argument for conducting a randomized trial [19].

The main obstruction to the conduct of a randomized controlled trial of this product seems to have been its premature release onto the market, on the assumption that its efficacy was already established. It has been argued that the product is simply a replacement for the naturally occurring protein, that there are few important side-effects and it might therefore be of some benefit. This proposition seems open to question; the product may indeed have proven biochemical activity against leucocyte elastase, the presumed harmful agent, but must be administered by intravenous infusion at not less than weekly intervals rather than being released from the liver into the blood in the normal continuous manner. It is surely unsatisfactory to find that a major pharmaceutical company is able to release a product onto the market without proving its efficacy in a properly controlled randomized trial.

It is now over $10 \mathrm{yrs}$ since AT replacement therapy became commercially available. It is to be hoped that the current Danish/Dutch randomized trial has sufficient power to address the question; otherwise the prospects of conducting a randomized trial seem further away than ever, since so many of the patients recruited with such effort have already started on this therapy. Neither they nor their medical attendants would take kindly to the proposal that they should now take part in a randomized controlled trial of the treatment they are already receiving and had previously believed to be effective. The dilemma we now face emphasizes (hardly for the first time) the necessity of undertaking a randomized controlled trial as early as possible during the development of any unproven therapy.

\section{References}

1. Seersholm N, Wencker M, Banik N, et al. Does alpha-1antitrypsin augmentation therapy slow the annual 
decline in FEV1 in patients with severe hereditary alpha1-antitrypsin deficiency? Eur Respir J 1997; 10: 2260-2263.

2. Gadek JE, Klein HG, Holland PV, Crystal RG. Replacement therapy of alpha-1-antitrypsin deficiency. Reversal of protease-antiprotease imbalance within the alveolar structures of PiZ subjects. J Clin Invest 1981; 68: $1158-1165$.

3. Burrows B. A clinical trial of efficacy of antiproteolytic therapy: can it be done? Am Rev Respir Dis 1983; 127: S42-S43.

4. Gadek JE, Crystal RG. Experience with replacement therapy in the destructive lung disease associated with severe alpha-1-antitrypsin deficiency. Am Rev Respir Dis 1983; 127: S45-S46.

5. Wu MC, Eriksson S. Lung function, smoking and survival in severe alpha-1-antitrypsin deficiency, PiZZ. $J$ Clin Epidemiol 1988; 41: 1157-1165.

6. Hein RH, Van Beveren SM, Shearer MA, Coan MH, Brockway WJ. Production of alpha 1-proteinase inhibitor (human). Eur Respir J 1990; 3: Suppl. 9, 16s-20s.

7. Burnouf T, Constans J, Clerc A, Descamps J, Martinache L, Goudemand M. Biochemical and biological properties of an alpha-1-antitrypsin concentrate. Vox Sang 1987; 52: 291-297.

8. Coan MH, Dobkin MB, Brockway WJ, Mitra G. Characterisation and virus safety of alpha-1-proteinase inhibitor. Eur Respir J 1990; 3: Suppl. 9, 35s-38s.

9. Hubbard RC, Crystal RG. Alpha-1-antitrypsin augmentation therapy for alpha-1-antitrypsin deficiency. Am J Med 1988; 84(6A); 52-62.

10. Schmidt EW, Rasche B, Ulmer WT, et al. Replacement therapy for alpha-1-protease inhibitor deficiency in PiZ subjects with chronic obstructive lung disease. Am J Med 1988; 84(6A): 63-69.
11. Hutchison DCS, Tobin MJ, Cooper D, Lowe D. Longitudinal studies in alpha-1-antitrypsin deficiency: a survey by the British Thoracic Society. In: Taylor JC, Mittman C, eds. Pulmonary emphysema and proteolysis. New York, Academic Press, 1987; pp. 7-16.

12. Brantly ML, Paul LD, Miller BH, Falk RT, Wu M, Crystal RG. Clinical features and history of the destructive lung disease associated with alpha-1-antitrypsin deficiency of adults with pulmonary symptoms. Am Rev Respir Dis 1988; 138: 327-336.

13. Evald T, Dirksen A, Keittelmann S, Viskum K, KokJensen A. Decline in pulmonary function in patients with alpha-1-antitrypsin deficiency. Lung 1990; 168 (Suppl): 579-585.

14. Hutchison DCS. Treatment of alpha-1-antitrypsin deficiency and prospects for a controlled trial. Eur Respir $J$ 1990; 3: Suppl. 10, 271s.

15. Seersholm N, Kok-Jensen A, Dirksen A, Decline in FEV1 among patients with severe hereditary alpha-1-antitrypsin deficiency type PiZ. Am J Respir Crit Care Med 1995; 152: 1922-1925.

16. The Alpha-1-Antitrypsin Deficiency Registry Study Group. A registry of patients with severe deficiency of alpha-1-antitrypsin: design and methods. Chest 1994; 106: 1223-1232.

17. McElvaney NG, Stoller JK, Buist AS, et al. and the Alpha-1-Antitrypsin Deficiency Registry Study Group. Baseline characteristics of enrollees in the National Heart, Lung and Blood Institute Registry of alpha-1-antitrypsin deficiency. Chest 1997; 111: 394-403.

18. Pocock SJ. Clinical Trials: A Practical Approach. Chapter 4. Chichester, UK, John Wiley, 1983; pp. 50-65.

19. Hill AB. Medical ethics and controlled trials. Br Med J 1963; i: 1043-1049. 